\title{
A Study of Work Stress and Health-Promoting Lifestyles among Health Care Workers at Base Hospital Kalmunai (North) in Sri Lanka
}

\author{
Dr. R. Muraleeeswaran ${ }^{1}$, Dr. M. Thenuka ${ }^{2}$ \\ ${ }^{1}$ Medical Superintendent, Base Hospital Kalmunai( North).Sri Lanka, Principal Investigator \\ ${ }^{2}$ Dental surgeon, Divisional hospital, Santhiveli, Sri lanka
}

\begin{abstract}
Background: Healthcare workers including Doctors, nurses, medical technicians and Minor staff experience high levels of occupational stress as a result of heavy workloads, extended working hours and time-related pressure. The aims of this study were to investigate factors associated with work stress among hospital staff members and to evaluate their health-promoting lifestyle behaviors. Methods: We conducted a cross-sectional study from May 1, 2015 to July 30, 2015 and recruited 400 professional staff from Base Hospital kalmunai(North) in Sri Lanka using purposive sampling. Demographic data and self-reported symptoms related to workrelated stress were collected. Each subject completed the Chinese versions of the Job Content Questionnaire (C-JCQ) and The HealthPromoting Lifestyle Profile (HPLSP). Linear and binary regression analyses were applied to identify associations between these two measurements and subjects' characteristics, and associations between the two measurements and stress symptoms. Results: Higher health care workers workloads are associated with burnout and job dissatisfaction, precursors to voluntary turnover that contribute to the understaffing of staff in hospitals and poorer patient outcomes. Self-reported symptoms of work-related stress included $64.4 \%$ of subjects reporting nervousness, 33.7\% nightmares, $44.1 \%$ irritability, $40.8 \%$ headaches, $35.0 \%$ insomnia, and $41.4 \%$ gastrointestinal upset. All items on the HPLSP correlated negatively with stress-related symptoms except for irritability, indicating an association between subjects' symptoms and a poor quality of health-promoting lifestyle behaviors. Conclusions: The results also suggested that better performance on or a higher frequency of health-promoting life-style behaviors might reduce the chances of hospital staff developing stress-related symptoms. We revealed that high demands, little decision-making authority, and low levels of social support were associated with the development of stress-related symptoms.. Our report may contribute to the development of educational programs designed to encourage members of high stress groups among the hospital staff to increase their health-promoting behaviors. It needs to be addressed by health care managers to implement effective coping strategies
\end{abstract}

Keywords: Healthcare workers, base hospital, stress, health promoting life style

\section{Background}

Healthcare workers in Sri L ankan hospitals are exposed to high levels of occupational stress resulting from heavy workloads, extended working hours . Hospital staff members, including physicians and nurses, are at a higher risk of suffering from depressive disorders than is the general population [1]. Hospital staff nurses who had frequent overtime had difficulties in staying awake on duty and reduced sleep times, and had nearly triple the risk of making an error [2].

Recently, considerable concern about job stress has given rise to a theoretical approach that focuses on a demandcontrol-support model of job strain, as proposed by Karasek et al. This model predicts that job strain will occur when psychological work demands are high and the worker's job control is low, while a low level of workplace social support will increase the risk of negative health outcomes. based on the demand-control-support model. The model predicts that job strain will occur when the psychological demands of the job are high and the worker's decision-making latitude is low, while a low level of support increases the risk of negative outcomes [4]].

A study of nurses in Sri Lanka, found that occupational stress was associated with young age, marital status (widowed/divorced/separated), high psychological demand, low workplace support, and threat of assault at work. A lower score for general health was associated with low job control, high psychological demand, and perceived occupational stress. A lower mental health score was associated with low job control, high psychological demand, low workplace support, and perceived occupational stress [ㄷ].

While the JCQ is able to evaluate psychosocial aspects of workplace stress, it does not consider individual personalities or lifestyle factors that may influence responses to those stressors. Job stress has been linked to a range of adverse physical and mental health outcomes, such as cardiovascular disease, insomnia, depression, and anxiety [6]. Increasing employee participation and control through workplace reorganization based on the "demand-controlsupport" model improved both psychological and physical health [7].

A Health-Promoting Lifestyle Profile (HPLSP) scale was developed by Walker based on this concept [8]. Healthprotecting behavior, an expression of the stabilizing tendency of humans, is directed toward decreasing the individual's probability of encountering illness [ㅁ] . A study conducted by Lee et al. found that nurses in Taiwan had a high level of work pressure but they had better strategies for coping with stress as well. On the HPLSP, self-actualization and health responsibility correlated negatively with work stresses. [10]. 


\section{International Journal of Science and Research (IJSR) \\ ISSN (Online): 2319-7064 \\ Index Copernicus Value (2013): 6.14 | Impact Factor (2015): 6.391}

The present study proposed that, for the professional staff in a hospital, the extent of job stress (measured by the JCQ) and performance in health-promoting lifestyle (measured by HPLSP) may correlate with stress-related symptoms. To the best of our knowledge, no previous study has examined the correlations among the factors related to stress in a cross section of hospital staff professionals.

\section{Methods}

\section{Participants}

In this cross-sectional study, a total of 400 subjects who worked in Base Hospital kalmunai(North) in Sri Lankan, were selected based on purposively sampling (deliberate, non-random sampling of the target population) from May $1^{\text {st }}, 2015$ to July $30^{\text {th }}$, 2015. The retrieval rate was $72.5 \%$. After the study was explained to participants, all subjects provided written informed consent.

\section{Measurements}

Ssymptoms were chosen based on related articles in the literature [11-13] and discussion by a panel of experts. Cronbach's $\alpha$ coefficient for this part of the questionnaire was 0.87. Participants were also asked to complete two questionnaires: the Chinese version of Karasek's Job Content Questionnaire (C-JCQ) [14] and the HPLSP [15].

\section{Instruments}

The C-JCQ [14] is a modification of the scale originally developed by Karasek et al. [4]. It consists of three dimensions: psychosocial work demands (5 items), job control (skill discretion, decision-making authority; 9 items), and workplace social support (coworker social support, supervisor social support; 8 items). Each item is measured on a four-point Likert scale (1: strongly disagree to 4: strongly agree). The scale consists of a set of 24 items that assess six dimensions of healthy behavior: Selfactualization, Health responsibility, Nutrition, Exercise, Interpersonal support, and Stress management. The Chinese version of the scale uses a four-point self-reported Likert scale scored as "never" (1), "sometimes" (2), "usually" (3), or "always" (4) to determine the frequency of reported behaviors. Internal reliability for the total scale was previously determined to be 0.90 with a range of 0.63 to 0.79 for the subscales [15] .

\section{Statistical Analysis}

Spearman's correlation analysis, point biserial correlation analysis, and point multiserial correlation analysis were utilized to show the coefficients of correlation. Binary logistic regression analysis was also utilized to identify symptoms of work-related stress while considering subjects' characteristics, JCQ, and HPLSP. All statistical assessments were considered significant at $p<0.05$. Statistical analyses were performed using SPSS 15.0 statistical software (SPSS Inc, Chicago, IL, USA).

\section{Results}

Among the 400 subjects, 127 were male and 273 were female. Table 1 shows the demographic characteristics and stress-related symptoms of the 400 subjects. Overall, 192 (48.\%) worked as minor staff, 128 (32\%) as nursing staff, 60
(15\%) as medical technicians, and 20(5.\%) as doctors. Among all subjects, 244(61\%) were married and 156 (39\%) were single;260 (65\%) had completed college or university. The average work experience of all subjects was 9.88 years $(\mathrm{SD}=6.46)$ and the time period of average daily work was 8.77 hours $(\mathrm{SD}=1.66)$. For self-reported symptoms of work-related stress, 256 (64.\%) of the subjects reported being nervous,13 6 (34\%) had nightmares, 176 (44.\%) had irritability, 160 (40.\%) had headache, 140 (35\%) had insomnia, and 164 (41.\%) had gastrointestinal upset.

Table 1: Subjects' demographic characteristics and workrelated symptoms $(\mathrm{N}=400)$

\begin{tabular}{|l|l|}
\hline Variables Job position \\
\hline \multicolumn{2}{|c|}{$(\mathbf{N}=\mathbf{4 0 0})$} \\
\hline Doctors & $20(5)$ \\
\hline Nurse Marriage status \\
\hline Medical technician staff & $128(32)$ \\
\hline Minor staff & $60(15.0)$ \\
\hline \multicolumn{2}{|c|}{ Education } \\
\hline Married & $244(61)$ \\
\hline Not married & $148(37)$ \\
\hline Other & $140(35)$ \\
\hline \multicolumn{2}{|c|}{ Symptoms of work-related stress } \\
\hline High school & $260(65)$ \\
\hline College or University & $9.88 \pm 6.46$ \\
\hline Work experience, years & $136(64)$ \\
\hline Daily work time, hours & $176(44)$ \\
\hline \multicolumn{2}{|c|}{. } \\
\hline Nervousness & $160(40)$ \\
\hline Nightmares & $140(35)$ \\
\hline Irritability & $164(41)$ \\
\hline Headaches & \\
\hline Insomnia & \\
\hline Gastrointestinal upset & \\
\hline
\end{tabular}

Data are represented as $\mathrm{n}(\%)$ for categorical variables and mean \pm SD for continuous variables.

Table $\underline{2}$ summarizes the measurements from the C-JCQ and HPLSP questionnaires. Average scores for each subcategory of the C-JCQ were: $13.87 \pm 2.11$ for psychological demands on the job, $16.82 \pm 2.37$ for discretion in use of skills, $\quad 7.83 \pm 1.36$ for decision-making authority, $12.17 \pm 1.62$ for coworker social support, and $11.26 \pm 2.09$ for supervisor social support. The outcomes on HPLSP measurement showed that both exercise $(7.83 \pm 2.15)$ and stress management $(9.90 \pm 2.11)$ had relatively low scores. The total score for health-promoting life-style reached only $64.47 \pm 11.19$ with a range from 28 to 106 . 


\section{International Journal of Science and Research (IJSR) \\ ISSN (Online): 2319-7064 \\ Index Copernicus Value (2013): 6.14 | Impact Factor (2015): 6.391}

Table 2: Summary of measurements on Job Content Questionnaires (JCQ) and health-promoting lifestyle profile (HPLSP) for all 400subjects ${ }^{\text {a }}$

\begin{tabular}{|c|c|c|}
\hline Variables & mean $\pm S D$ & Range \\
\hline \multicolumn{3}{|c|}{ Job Content Questionnaire } \\
\hline demands of the job & $13.87 \pm 2.11$ & $(7-20)$ \\
\hline Discretion $\quad$ in use of skills & $16.82 \pm 2.37$ & $(6-23)$ \\
\hline Decision-making authority & $7.83 \pm 1.36$ & $(3-12)$ \\
\hline Coworker $_{\text {social support }}^{\dagger}$ & $12.17 \pm 1.62$ & $(4-16)$ \\
\hline social support $^{\dagger}$ & $11.26 \pm 2.09$ & $(4-16)$ \\
\hline \multicolumn{3}{|c|}{ Health-promoting lifestyle profiles } \\
\hline Self-actualization & $10.59 \pm 2.51$ & $(4-16)$ \\
\hline Health responsibility & $10.66 \pm 2.70$ & $(5-20)$ \\
\hline Exercise & $7.83 \pm 2.15$ & $(4-15)$ \\
\hline Nutrition & $14.44 \pm 3.54$ & $(6-24)$ \\
\hline $\begin{array}{ll}\text { Interpersonal } & \text { support }\end{array}$ & $11.05 \pm 2.07$ & $(4-16)$ \\
\hline Stress management & $9.90 \pm 2.11$ & $(4-16)$ \\
\hline $\begin{array}{c}\text { Total score of health-promoting } \\
\text { lifestyle profile }\end{array}$ & $64.47 \pm 11.19$ & $(28-106)$ \\
\hline
\end{tabular}

${ }^{\mathrm{a}}$ Data are represented as mean $\pm \mathrm{SD}$ and range (min. - max.). $\dagger$ Those two items asked for the need for social support. In other words, a higher score stands for not enough social support from either coworkers or supervisor.

Table $\underline{3}$ shows the correlations between subjects' characteristics and C-JCQ categories. The results show that gender was positively correlated with psychological demands, but negatively correlated with discretion in use of skills as female staff had greater psychological demands but less discretion in their use of skills. Job position ranked in the order of physicians, nurses, medical technician staff and administrative staff was negatively correlated with psychological demands, discretion in use of skills and decision-making authority, as physicians had greater psychological demands, discretion in their use of skills and decision-making authority than did nurses, followed by medical technician staff, and administrative staff.

Table 3: Correlation of Job Content Questionnaire with subjects' characteristics $(\mathrm{N}=755)$

\begin{tabular}{|c|c|c|c|c|c|c|c|c|c|c|}
\hline & \multicolumn{2}{|c|}{$\begin{array}{c}\text { Psychological } \\
\text { Demands of Job }\end{array}$} & \multicolumn{2}{|c|}{$\begin{array}{c}\text { Discretion In Use of } \\
\text { Skills }\end{array}$} & $\begin{array}{c}\text { Decision-making } \\
\text { authority }\end{array}$ & \multicolumn{4}{|c|}{$\begin{array}{c}\text { Coworker social } \\
\text { support }^{\mathrm{a}}\end{array}$} & $\begin{array}{c}\text { Supervisor social } \\
\text { support }^{\mathrm{a}}\end{array}$ \\
\hline & $\mathrm{r}$ & $\mathrm{p}$-value & $\mathrm{r}$ & $\mathrm{p}$-value & $\mathrm{r}$ & $\mathrm{p}$-value & $\mathrm{r}$ & $\mathrm{p}$-value & $\mathrm{r}$ & $\mathrm{p}$-value \\
\hline Gender & .085 & $0.018^{*}$ & -.127 & $<.001^{* * *}$ & -.057 & 0.113 & .011 & 0.764 & -.015 & 0.682 \\
\hline Job position & -.235 & $<.001^{* * *}$ & -.297 & $<.001^{* * *}$ & -.103 & $0.004^{* *}$ & .014 & 0.702 & -.010 & 0.785 \\
\hline Work experience, years & .002 & 0.947 & .146 & $<.001^{* * *}$ & .115 & $0.001^{* *}$ & -.095 & $0.008^{* *}$ & -.079 & $0.027^{*}$ \\
\hline Daily work times, hours & .326 & $<.001^{* * *}$ & .296 & $<.001^{* * *}$ & .107 & $0.003^{* *}$ & -.016 & 0.647 & -.033 & 0.358 \\
\hline
\end{tabular}

r, coefficient of correlation of Job Content Questionnaire with gender was derived through the point biserial correlation analysis (male, 1; female, 2); with job position through the point multiserial correlation analysis (physician, 1; nurse, 2; medical technician staff, 3; administrative staff, 4); with work experience or with daily work times through Spearman's correlation analysis.

${ }^{*} \mathrm{P}<0.05, \quad{ }^{* *} \mathrm{P}<0.01, \quad{ }^{* * *} \mathrm{P}<0.001, \quad$ indicate significant correlation between health-promoting life-style profiles and characteristics.

a These two items indicate perceived needs for social support. In other words, a higher score stands for not enough social support from either coworkers or supervisors.
Longer work experience was positively correlated with discretion in use of skills and decision-making authority but showed a negative correlation with coworker social support and supervisor social support. (Table $\underline{3}$ ) Daily work times were positively correlated with psychological demands, discretion in use of skills and decision-making authority. (Table $\underline{3}$ )

The correlation of subjects' characteristics with HPLSP categories is shown in Table $\underline{4}$. The total HPLSP score was positively correlated with job position $(\mathrm{r}=0.168, \mathrm{P}<0.001)$ but negatively correlated with daily work time $(\mathrm{r}=-0.127$, $\mathrm{P}<0.001)$. Physicians had the lowest score in HPLSP among the four positions, followed by nurses, medical technician staff, and administrative staff in that order.

Table 4: Correlation of Health-promoting life-style profiles with subjects' characteristics $(\mathrm{N}=400)$

\begin{tabular}{|c|c|c|c|c|c|c|c|c|c|c|c|c|c|c|}
\hline \multirow[t]{2}{*}{ Characteristics } & \multicolumn{2}{|c|}{$\begin{array}{c}\text { Self- } \\
\text { actualization }\end{array}$} & \multicolumn{2}{|c|}{$\begin{array}{l}\text { Health } \\
\text { responsibility }\end{array}$} & \multicolumn{2}{|c|}{ Exercise } & \multicolumn{2}{|c|}{ Nutrition } & \multicolumn{2}{|c|}{$\begin{array}{l}\text { Interpersonal } \\
\text { support }\end{array}$} & \multicolumn{2}{|c|}{$\begin{array}{c}\text { Stress } \\
\text { management }\end{array}$} & \multicolumn{2}{|c|}{$\begin{array}{l}\text { Total score for } \\
\text { health-promoting } \\
\text { life-style }\end{array}$} \\
\hline & $r$ & P-value & $\mathrm{r}$ & $\begin{array}{c}\mathrm{P}- \\
\text { value }\end{array}$ & $r$ & P-value & $r$ & P-value & $\mathrm{r}$ & $\begin{array}{c}\mathrm{P}- \\
\text { value }\end{array}$ & $r$ & P-value & $r$ & P-value \\
\hline Gender & -0.057 & 0.111 & 0.009 & 0.805 & -0.059 & 0.100 & -0.066 & 0.068 & 0.051 & 0.156 & 0.005 & 0.889 & -0.032 & 0.368 \\
\hline Job position & 0.122 & $0.001^{* *}$ & 0.019 & 0.599 & 0.084 & $0.019^{*}$ & 0.269 & $<.001^{* * *}$ & 0.065 & 0.071 & 0.121 & $0.001^{* *}$ & 0.168 & $<.001^{* * *}$ \\
\hline $\begin{array}{l}\text { Work } \\
\text { experience, } \\
\text { years }\end{array}$ & 0.062 & 0.087 & 0.078 & $0.030^{*}$ & 0.015 & 0.672 & 0.198 & $<.001^{* * *}$ & -0.018 & 0.613 & -0.001 & 0.977 & 0.087 & 0.015 \\
\hline $\begin{array}{l}\text { Daily work } \\
\text { times, hours }\end{array}$ & -0.072 & $0.045^{*}$ & -0.038 & 0.290 & -0.094 & $0.009^{* *}$ & -0.188 & $<.001^{* * * *}$ & -0.018 & 0.623 & -0.095 & $0.008^{* *}$ & -0.127 & $<.001^{* * *}$ \\
\hline
\end{tabular}




\section{International Journal of Science and Research (IJSR) \\ ISSN (Online): 2319-7064 \\ Index Copernicus Value (2013): 6.14 | Impact Factor (2015): 6.391}

$r$, coefficient of correlation of health-promoting life-style profiles with gender was derived through the point biserial correlation analysis (male, 1; female, 2); with job position through the point multiserial correlation analysis (physician, 1; nurse, 2; medical technician staff, 3; administrative staff, 4); with work experience or with daily work times through Spearman's correlation analysis.

${ }^{*} \mathrm{P}<0.05, \quad{ }^{* *} \mathrm{P}<0.01, \quad{ }^{* * *} \mathrm{P}<0.001, \quad$ indicate significant correlation between health-promoting life-style profiles and characteristics.

Among the subcategories of HPLSP, most (Selfactualization, Exercise, Nutrition, Stress management) were positively correlated with job position. Physicians had less self-actualization, fewer chances to exercise, cared less about nutrition, and did not manage stress well. They were followed by nurses, medical technician staff, and administrative staff in that order. (Table $\underline{4}$ ) For C-JCQ items, scores on psychological demands of the job and decisions to utilize skills had a positive correlation with stress-related symptoms, except for irritability; however, decision-making authority scores had a negative correlation with stress-related symptoms, except for irritability. Both the scores for coworker social support and supervisor social support had negative correlations with stress-related symptoms except for nightmares and irritability. All items on the health-promoting life-style profiles had a negative correlation with stress-related symptoms, except for irritability.

\section{Discussion}

The Hospital staff workforce is experiencing greater workloads resulting from shorter hospital stays ,rising average patient acuity, fewer support resources, and a national staff shortage. Relationships were also shown between job category and dimensions of the JCQ. Male workers had fewer psychological demands on the job than did females but had greater discretion in utilizing their skills. Hospital nursing staff, medical technicians and administrative staff had significantly less discretion in utilizing their skills and decision-making authority than did physicians. Longer work experience was associated with significantly higher discretion in utilizing skills and decision-making authority among all workers.. Psychological demands on the job were somewhat associated with gender and daily work time. In terms of symptoms, being female, having a longer work experience, and working longer hours each day were associated with significantly greater stress-related symptoms, except for irritability

As in the study by Shen et al. [4], lower general health scores measured by the JCQ were associated with low job control, high psychological demand, and perceived occupational stress. A lower mental health score was associated with low job control, high psychological demand, low workplace support, and perceived occupational stress. In the present study, low job control was represented by low scores for decision-making authority and discretion in utilization of skills. We found that scores for psychological demands on the job and discretion in utilizing skills correlated positively with stress-related symptoms while decision-making authority scores correlated negatively with stress-related symptoms.

McElligott et al. [15] examined the health-promoting lifestyle behaviors of acute-care nurses using the Health Promotion Model. Their results showed overall low scores for health-promoting behavior, with particular weaknesses in stress management and physical activity. In our study, we also found that almost all items on the HPLSP correlated negatively with stress-related symptoms, indicating an association between high-quality health-promoting lifestyle behavior and fewer stress-related symptoms.

In the present study, nurses sensed a lack of social support from peers and supervisors and, in expressing a need for more social support, placed a high value on relationships at work as being an important aspect of the work environment. Work relationships were also cited as a direct source of stress by Hope et al. as hospital nurses who experienced high work stress were more apt to seek professional support and the support of family and friends or "having a good cry" [16]. Seeking support from coworkers or supervisors may actually represent health-protecting behavior that could help diffuse the impact of stressors in the workplace. Based on our results regarding the expressed need for support among hospital staff, measures such as conflict resolution and peer support groups could help increase health-promoting skills and thereby reduce the development of stress-related symptoms.

They recommended implementation of standard operating procedures, security measures and increases in the quantity and quality of stress relief courses [17]. Other studies have suggested that health-promotion skills should be integrated into nursing education. Many researchers in Taiwan have studied job stress, coping strategies and health promoting behavior among hospital staffs [4, 13, 17, ], and in other occupations [19(]. The present study is the first to comprehensively investigate associations between scores on the C-JCQ and HPLSP and stress-related symptoms among hospital staff members at Base Hospital kalmunai (North) in Sri Lanka.

\section{Conclusions}

The health care workers burnout affects the patients satisfaction with quality of care. It needs to be addressed by health care managers to implement effective coping strategies.

Little decision-making authority and a lack of social support from either coworkers or supervisors are associated with the development of stress-related symptoms. Better performance in or higher frequency of health-promoting life-style behaviors might reduce the chances of developing stressrelated symptoms. We suggest that our results may be useful in the development of educational programs designed to encourage highly stressed hospital staff members to pay more attention to health-promoting lifestyles and to increase health-promoting behaviors . 


\section{References}

[1] Alpert JS: Physician depression. Am J Med 2008, 121:643.PubMedView Article

[2] Rogers AE, Hughes RG: The Effects of Fatigue and Sleepiness on Nurse Performance and Patient Safety. Patient Safety and Quality: An Evidence-Based Handbook for Nurses. Rockville (MD), Agency for Healthcare Research and Quality (US); 2008. Apr. Chapter 40. Advances in Patient Safety

[3] Karasek R: Brisson, Kawasaki N, Houtman I, Bongers P, Amick B: The Job Content Questionnaire: an instrument for internationally comparative assessments of job characteristics. $J$ Occup Health Psychol 1998,3(4):322355.PubMedView Article

[4] Shen HC, Cheng Y, Tsai PJ, Lee SH, Guo YL: Occupational stress in nurses in psychiatric institutions in Taiwan. $J$ Occup Health 2005,47(3):218-225.PubMedView Article

[5] Nakao M: Work-related stress and psychosomatic medicine. Biopsychosoc Med 2010,4(1):4.PubMedView Article

[6] Egan M, Bambra C, Thomas S, Petticrew M, Whitehead M: Thomson H. The psychosocial and health effects of workplace reorganisation. 1. A systematic review of organisational-level interventions that aim to increase employee control. Epidemiol Community Health 2007,61(11):945-954.

[7] Walker SN, Sechrist KR, Pender NJ: The HealthPromoting Lifestyle Profile: development and psychometric characteristics. Nurs Res 1987,36(2):76-81.PubMedView Article

[8] Pender NJ, Walker SN, Stromberg MF, Sechrist KR: Predicting health-promoting lifestyles in the workplace. Nurs Res1990, 39:326-332.PubMedView Article

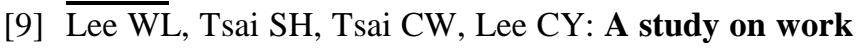
stress, stress coping strategies and health promoting lifestyle among district hospital nurses in Taiwan. $J$ Occup Health 2011,53(5):377-83.PubMedView Article

[10] $\overline{\text { Krantz }}$ G, Berntsson L, Lundberg U: Total workload, work stress and perceived symptoms in Swedish make and female white-collar employees. Eur $J$ Public Health 2005,15(2):209-214.PubMedView Article

[11] Ekvall Hansson E, Hakansson E, Raushed A, Hakansson A: Multidisciplinary program for stressrelated disease in primary health care. $J$ MultidiscipHealthc 2009, 2:61-65.PubMedView Article

[12] Estryn-Behar M, Kaminski M, Peigne E, Bonnet N, Vaichere E, Gozlan C, Azoulay S, Giorgi M: Stress at work and mental health status among female hospital workers. $\mathrm{Br} J$ Ind Med 1990,47(1):2028.PubMed

[13] Wang LJ, Chen CK, Hsu SC, Lee SY, Wang CS, Yeh WY: Active Job, Healthy Job? Occupational stress and depression among hospital physicians in Taiwan. Ind Health 2011, 49:173-184.PubMedView Article
[14] Wei MH, Lu CM: Development of the short-form Chinese health-promoting liestyle profile. $J$ Health Edu 2005, 24:25-46.

[15] McElligott D, Siemers S, Thomas L, Kohn N: Health promotion in nurses: is there a healthy nurse in the house? ApplNurs Res 2009,22(3):211215.PubMedView Article

[16] Hope A, Kelleher CC, O'Connor M: Lifestyle practices and the health promoting environment of hospital nurses. J AdvNurs 1998,28(2):438-447.PubMedView Article

[17] Chen CK, Lin C, Wang SH, Hou TH: A study of job stress, stress coping strategies, and job satisfaction for nurses working in middle-level hospital operating rooms. J Nurs Res 2009,17(3):199211.PubMedView Article 